\title{
APPLICABILITY OF DISPERSION MODEL TO A PACKED BED REACTOR WITH AN IRREVERSIBLE CHEMICAL REACTION OF THE 2ND ORDER*
}

\author{
KEI MIYANAMI, MUNETAKE SATO AND TAKEO YANO \\ Department of Chemical Engineering, University of Osaka Prefecture, \\ Sakai, Japan
}

\begin{abstract}
Applicability of the one-dimensional dispersion model as a flow model of a packed-bed chemical reactor is discussed for the hydrolysis of ethyl acetate by sodium hydroxide. An experimental technique, easily applied by purging one of the reactants concerned from a flow system with the other, is developed to study fluid mixing effectively in a flow system accompanying chemical reaction. Called dual-step response method, it is proved to be an effective method.
\end{abstract}

\section{Introduction}

Fluid mixing in a packed bed is macroscopically expressed by a dispersion model, and the degree of mixing in the bed is represented by a model parameter, the longitudinal dispersion coefficient. Various studies of fluid mixing in a variety of packed beds have been made experimentally and theoretically. Dynamic and static characteristics of the packed bed as a chemical flow reactor, however, have been studied only theoretically by applying various flow models ${ }^{4,5,8)}$.

In this paper, applicability of the one-dimensional dispersion model $\left.(1-\mathrm{DDM})^{10}\right)$ to a packed-bed chemical reactor is studied experimentally for cases where an irreversible chemical reaction of the 2 nd order occurs in the bed.

\section{Experimental}

Fig. 1 shows a schematic flow diagram of the apparatus. The details of the packed-bed reactor are given in Fig. 2. The reactor consists of glass tubes of $50 \mathrm{~mm}$ i.d. and lengths of 250, 500 and $1000 \mathrm{~mm}$, packed randomly with $10 \mathrm{~mm}$ ceramic Raschig rings or $7 \mathrm{~mm}$ glass spheres. The void fractions were 0.537 when packed with the Raschig rings and 0.399 with the spheres.

Three independent liquid pumping systems were prepared for circulation of liquids. Flow rates of the liquids were adjusted by needle valves $V_{1}, V_{2}$ and $V_{3}$, measured by flow meters (rotameters) $R_{1}, R_{2}$ and $R_{3}$, respectively, and then the liquids were fed into the reactor.

* Received on September 23, 1971

Presented at the 32nd Annual Meeting of the Soc. of Chem. Engrs., Japan, at Tokyo, April, 1967.
To apply step inputs of the concentrations in the fluid flow to the reactor, the liquids from each of the three pumping systems into the reactor were interchanged through solenoid valves $V_{4}, V_{5}$ and $V_{6}$, which can be activated simultaneously. To avoid any change of flow rates on the introduction of the step inputs, variable-height overflow tubes $\mathrm{O}_{4}$ and $\mathrm{O}_{5}$ were attached to the outlets of flow meters $R_{1}$ and $R_{2}$, respectively. While the liquid from tank $T_{1}$ is flowing into the reactor, the liquid from $\mathrm{T}_{2}$ is overflowing at a predetermined rate through $\mathrm{O}_{5}$ until the solenoid valves are activated. After activation, the liquid from $\mathrm{T}_{1}$ in turn overflows through $\mathrm{O}_{4}$ and the liquid of $\mathrm{T}_{2}$ enters the reactor.

The liquid leaving the reactor is exhausted through overflow tube $\mathrm{O}_{6}$.

1. Tracer step response

Fluid mixing in the packed bed was observed by means of tracer step responses and identified with the 1-DDM.

Potassium chloride solution $(\mathrm{KCl})$ of $0.01 \mathrm{~N}$ was used for the tracer. Water was stored in $\mathrm{T}_{1}$ and the $\mathrm{KCl}$ solution in $\mathrm{T}_{2}$. The step change of $\mathrm{KCl}$ concentration was introduced into the reactor by activating or deactivating the solenoid valves simultaneously. The $\mathrm{KCl}$ concentrations of entering and leaving solutions were determined continuously by measuring the electric conductivities of the solutions with instruments similar to the one described by Cairns and Prausnitz ${ }^{2}$. The conductivity cell consists of a pair of platinum wires of $2 \mathrm{~mm}$ diameter with $7 \mathrm{~mm}$ aperture. Two such cells, $\mathrm{C}_{1}$ and $\mathrm{C}_{2}$, are installed at the inlet and the outlet of the reactor, respectively.

2. Dual-step response with the 2 nd order irreversible chemical reaction ${ }^{11}$ )

To test whether the 1-DDM can be used to interpret the dynamic behavior of the packed bed as a chemical 


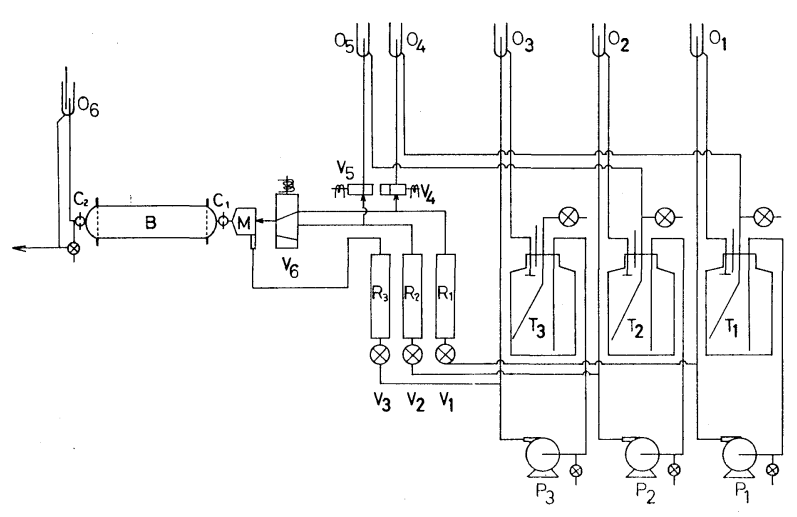

B : packed-bed reactor

$\mathrm{C}_{1}, \mathrm{C}_{2}$ : electric conductivity cell

$\mathrm{M}$ : pre-mixer

$\mathrm{P}_{1-3}$ : pump

$\mathrm{R}_{1-3}$ : flow-rate meter

$\mathrm{T}_{1-3}$ : liquid-storage tank

$\mathrm{V}_{1-3}$ : needle valve

$\mathrm{V}_{4-6}$ : solenoid sliding valve

$\mathrm{O}_{1-6}$ : overflowing tube

Fig. 1 Schematic diagram of the experimental apparatus

flow reactor, the reaction

$\mathrm{CH}_{3} \mathrm{COOC}_{2} \mathrm{H}_{5}+\mathrm{NaOH}=\mathrm{CH}_{3} \mathrm{COONa}+\mathrm{C}_{2} \mathrm{H}_{5} \mathrm{OH}$

was performed in the bed. This reaction is 2 nd order irreversible, and the rate equation is given by ${ }^{14)}$

$$
\begin{aligned}
& \frac{\mathrm{d}[\mathrm{NaOH}]}{\mathrm{d} t}=-k\left[\mathrm{CH}_{3} \mathrm{COOC}_{2} \mathrm{H}_{5}\right][\mathrm{NaOH}] \\
& \log _{10} k=-1780 / T_{r}+0.00754 T_{r}+2.75
\end{aligned}
$$

Ethyl acetate solution of $0.1 \mathrm{~mol} / l$ was stored in $T_{1}$ and sodium hydroxide solution in $\mathrm{T}_{2}$. The concentration of the $\mathrm{NaOH}$ solution was varied from 0.005 to $0.2 \mathrm{~N}$. By simultaneous activation or deactivation of the solenoid valves, the fluid stream into the reactor was changed from the ester solution to the $\mathrm{NaOH}$ solution (input-B in Fig. 3), or vice versa (input-A in Fig. 3). With this procedure, step changes of the concentrations of both ester and sodium hydroxide occur in the fluid stream into the reactor, as shown in Fig. 3 by the solid lines. Consequently, this method may be called the "dual-step response method". The responses were followed in terms of $\mathrm{NaOH}$ concentration at the outlet of the reactor by measuring the electric conductivity of the leaving solution. The responses are shown in Fig. 3 by dotted lines.

\section{Conversion of $\mathbf{N a O H}$ at steady state}

Static characteristics of the packed bed as a chemical flow reactor are also important to estimate the conversion of a reaction. Steady-state experiments were done as follows: Ethyl acetate solution was stored in $\mathrm{T}_{1}$ and sodium hydroxide solution in $\mathrm{T}_{3}$. These two liquids were well mixed by the premixer $M$ and then fed into the reactor. When the indications of the electric conductivity meters at the inlet and the outlet of the reactor became constant under a constant flow rate of the reactants, the output voltages were recorded. The liquid flow was then stopped. After the indications became constant again, they were also recorded.

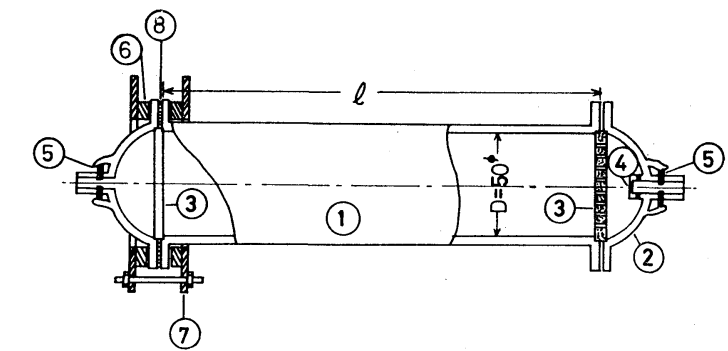

1: glass tube

2: covers

3: sieve plates

4: liquid distributer

5: platinum electrodes

6: sponge rubber

7: flange supporters

8: gaskets

Fig. 2 Details of the packed-bed chemical reactor
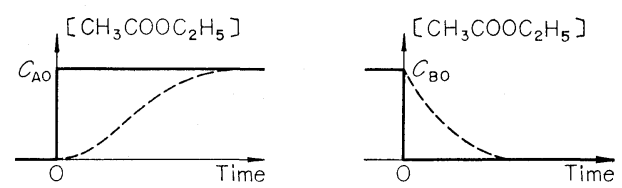

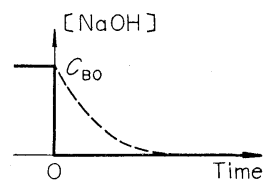

Input-A

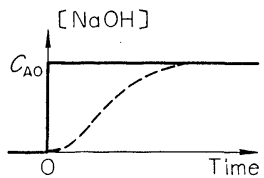

Input - B

Solid line : input

Dotted line : output

Fig. 3 Inputs applied to the reactor (dual-step input)

From these voltages with the inlet concentrations of $\mathrm{NaOH}$ and ester, the conversion of $\mathrm{NaOH}$ at the outlet of the reactor can be calculated ${ }^{6}$.

\section{Results and Discussion}

1. Tracer step response (calculations of the flow model parameters)

The variance $\sigma^{2}$ (the 2 nd order moment around the mean) of the residence time distribution of fluid in the reactor is defined as

$$
\sigma^{2}=\frac{\overline{t^{2}}}{(\bar{t})^{2}}-1
$$

where

$$
\begin{gathered}
\bar{t}=\int_{0}^{\infty} \Psi(t) \mathrm{d} t, \quad \overline{t^{2}}=2 \int_{0}^{\infty} t \Psi(t) \mathrm{d} t \\
\Psi(t)=1-F(t)
\end{gathered}
$$

The value of $\sigma^{2}$ was calculated by numerical integration of the normalized tracer step response, $F(t)^{13}$.

The model parameter $P e$ of the $1-D D M$ was evaluated from the relation:

$$
\sigma^{2}=2\left(P e-1+e^{-P e}\right) / P e^{2}
$$

by means of the Newton-Raphson method.

The tracer step response of the 1-DDM was calculated by means of Brenner's procedure ${ }^{1)}$ with the authors' modification $^{12)}$.

In Fig. 4, a comparison is made between typical experimental and model responses. The extent in Fig. 4 


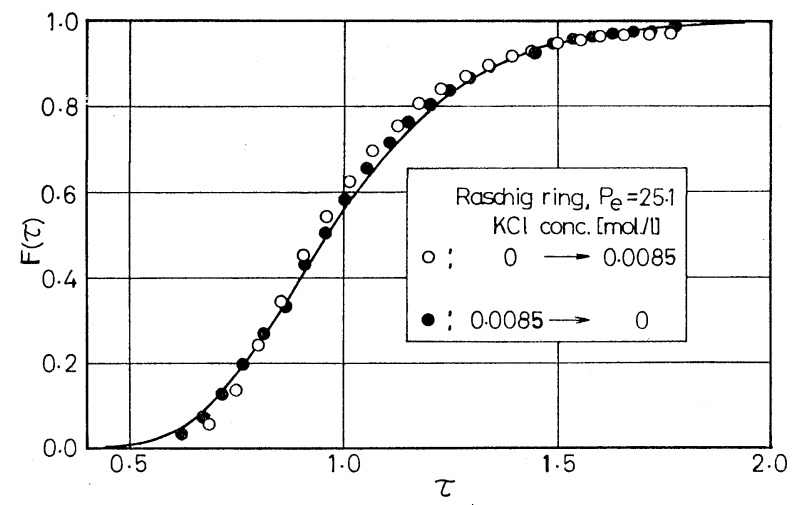

Fig. 4 Tracer step responses of the packed-bed reactor

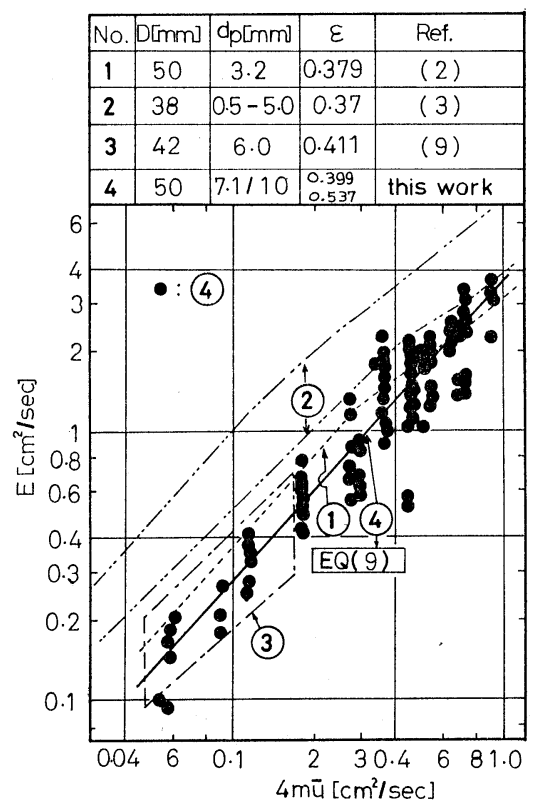

Fig. 5 Longitudinal dispersion coefficient of the packedbed chemical reactor

to which the model response was in agreement with the experimental one did not depend on changes of packing materials, length of the packed bed reactor or flow rate of the liquid.

Cairns and Prausnitz ${ }^{2)}$ arranged their experimental results as plots of the longitudinal dispersion coefficient $E$ against $4 m \bar{u} . \quad E$ is calculated from the relation

$$
E=\bar{u} l / P e,
$$

where $\bar{u}$ is given as

$$
\bar{u}_{i}=4 f / \pi D^{2} \varepsilon
$$

and $4 m$ is the hydraulic radius of the packing. Fig. 5 shows the relation between $E$ and $4 m \bar{u}$. In this figure, the results by Cairns \& Prausnitz ${ }^{2)}$, Carberry \& Bretton $^{3 \text { ? }}$ and Strang \& Geankoplis $\left.{ }^{9}\right)$ are also included for comparison. The present results are in good agreement with the data already published, and $E$ is approximately proportional to $4 m \bar{u}$. $E$ can be correlated with $4 m \bar{u}$ by the relation

$$
E=3.70[4 m \bar{u}]^{1.12}
$$

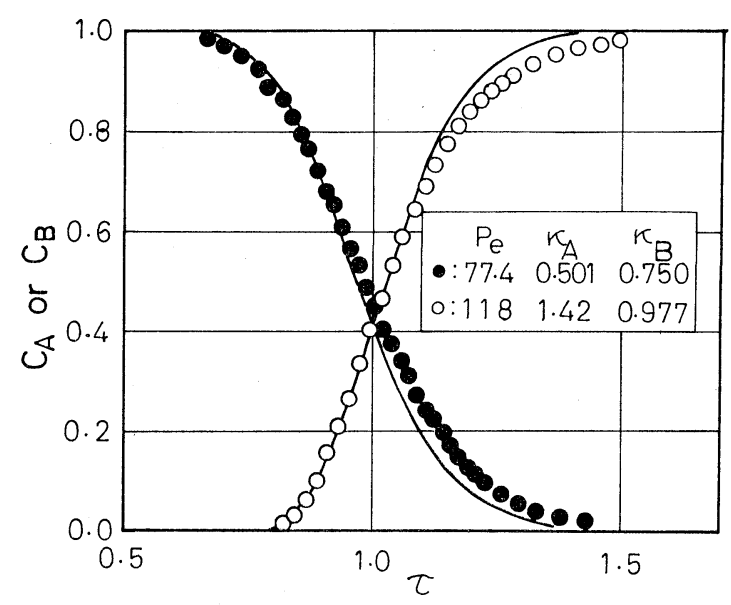

Fig. 6 Dual-step responses of the packed-bed chemical reactor with the 2 nd order reaction

This correlation is based on the experimental data of about 150 runs. The maximum deviation between the values of $E$ calculated from Eq.(9) and the experimental ones is about \pm 30 percent.

2. Dual-step response with the 2 nd order irreversible chemical reaction

It appears from the results in 1) that fluid mixing in the packed bed could be expressed by the 1-DDM. If the fluid entering the bed is changed instantaneously from a solution of species A to that of species B and there occurs an irreversible reaction of the 2nd order between $\mathrm{A}$ and $\mathrm{B}$, the responses of $\mathrm{A}$ and $\mathrm{B}$ are governed by Eq.(10):

$$
\begin{aligned}
& \frac{\partial c_{A}}{\partial \tau}= \frac{1}{P e} \frac{\partial^{2} c_{A}}{\partial \xi^{2}}-\frac{\partial c_{A}}{\partial \xi}-\kappa_{B} c_{A} c_{B} \\
& \frac{\partial c_{B}}{\partial \tau}= \frac{1}{P e} \frac{\partial^{2} c_{B}}{\partial \xi^{2}}-\frac{\partial c_{B}}{\partial \xi}-\kappa_{A} c_{A} c_{B} \\
& \text { at } \xi=0+, \quad-\frac{1}{P e} \frac{\partial c_{A}}{\partial \xi}=1-c_{A} \\
& \quad-\frac{1}{P e} \frac{\partial c_{B}}{\partial \xi}=-c_{B} \\
& \text { at } \xi=1-, \quad \frac{\partial c_{A}}{\partial \xi}=0, \quad \frac{\partial c_{B}}{\partial \xi}=0 \\
& \text { at } \tau=0, \quad c_{A}=0, \quad c_{B}=1
\end{aligned}
$$

In deriving Eq.(10), it is assumed that no fluid mixing occurs outside the bed. The parameters $P e$, $\kappa_{A}$ and $\kappa_{B}$ in Eq.(10) can be evaluated from the experimental conditions. $\kappa_{A}$ and $\kappa_{B}$ were varied as

$$
\kappa_{A}=0.434 \sim 4.46, \quad \kappa_{B}=0.107 \sim 7.50 \text { for input-A }
$$

and

$$
\kappa_{A}=0.182 \sim 8.36, \quad \kappa_{B}=0.500 \sim 4.97 \text { for input-B. }
$$

$P e$ was estimated by Eq.(9). Eq.(10) was solved numerically by means of the quasilinearization $\operatorname{method}^{7)}$. In Fig. 6, a comparison is made between typical experimental responses and model responses.

If $\mathrm{A}$ and $\mathrm{B}$ were completely segregated, no reaction between them would take place. Then the experimental dual-step response might become the same as the tracer step response and deviate from the solution of Eq.(10). The deviation also occurs if the 


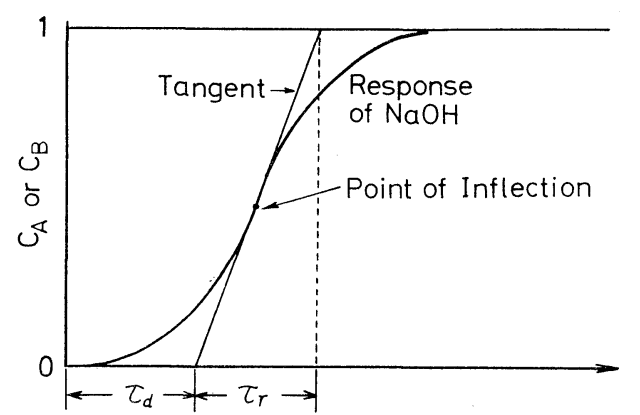

Fig 7 The definitions of $\boldsymbol{\tau}_{d}$ and $\boldsymbol{\tau}_{r}$

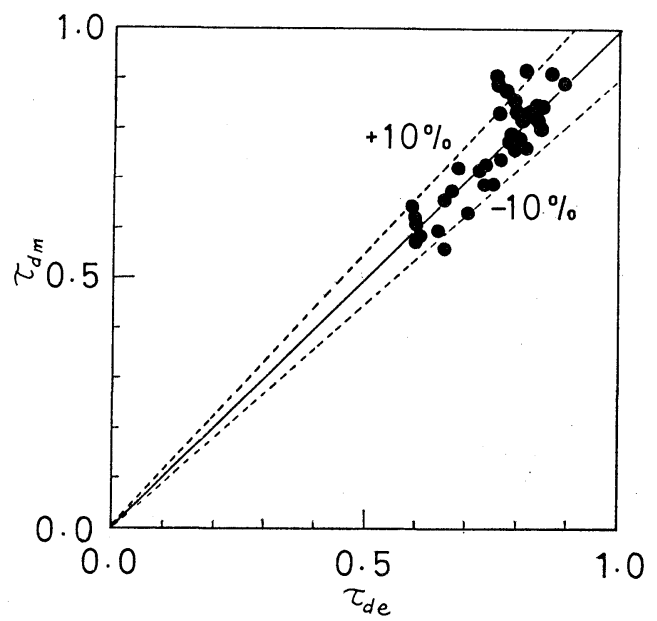

Fig. 8 Comparison of $\boldsymbol{\tau}_{d e}$ with $\boldsymbol{\tau}_{d m}$

actual mechanism of fluid mixing in the bed differs from that assumed in the 1-DDM. To discuss the applicability of the 1-DDM to the interpretation of the dual-step responses, the characteristics of the response $\tau_{r}$ and $\tau_{d}$, shown in Fig. 7 schematically, were evaluated from the experimental responses (they are denoted by $\tau_{r e}$ and $\tau_{d e}$ ) and the corresponding responses of the model $\left(\tau_{r m}\right.$ and $\left.\tau_{d m}\right) . \tau_{r}$ is the time interval between the points where the tangent line drawn at the inflection point of the response curve intersects the lines of $c_{A}$ or $c_{B}=0$ and $c_{A}$ or $c_{B}=1$, respectively, and $\tau_{d}$ is the time at which the tangent intersects the line of $c_{A}$ or $c_{B}=0$. Hence, $\tau_{r}$ represents the rise time of the response and $\tau_{d}$, the dead time. A pair of $\tau_{r}$ and $\tau_{d}$ can characterize a dualstep response. In Fig. 8, a comparison is made between $\tau_{d m}$ and $\tau_{d e}$, and $\tau_{r m}$ is compared with $\tau_{r e}$ in Fig. 9. From these two figures, it is clear that, although the estimates of $\tau_{d}$ by the model are in agreement with the observed ones to a precision of \pm 10 percent, the estimates of $\tau_{r e}$ deviate from the observed ones by \pm 30 percent.

By the dual-step response method, the applicability of the 1-DDM to the packed bed reactor can easily be examined more strictly than by the tracer step response method.

\section{Steady-state conversion of $\mathrm{NaOH}$}

Recording of the output voltages from the electric conductivity meters is shown in Fig. 10. Since these

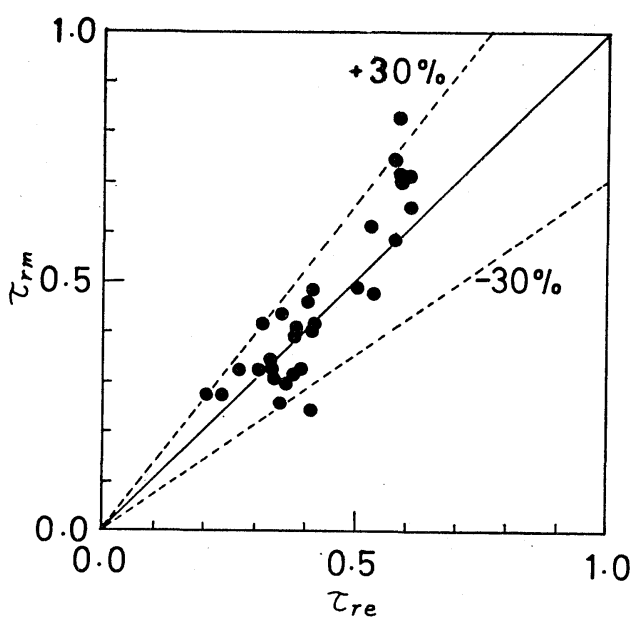

Fig 9 Comparison of $\boldsymbol{\tau}_{r e}$ with $\boldsymbol{\tau}_{r m}$

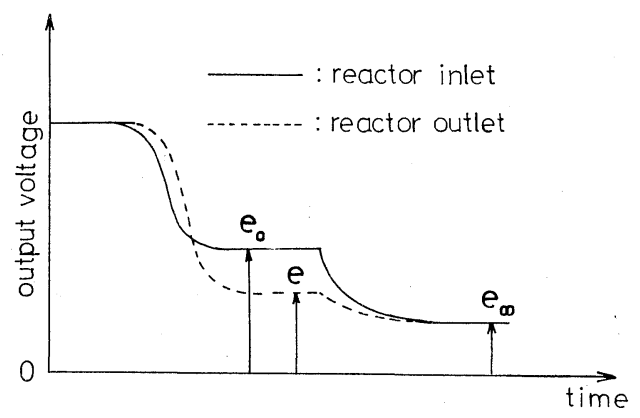

Fig. 10 Recording of the output voltages of the electric conductivity meters at steady state

voltages, $e_{0}, e$ and $e_{\infty}$ are proportional to the electric conductivities of the respective solutions, the conversion of $\mathrm{NaOH} \eta_{e}$ can be calculated by $\left.{ }^{6}\right)$

$$
\eta_{e}=\frac{e_{0}-e}{e_{0}-e_{\infty}} \alpha
$$

if the gains of the meters are adjusted to a certain identical level in advance.

Now, if one assumes the 1-DDM for fluid mixing in the packed bed, the model equation of the steady state becomes

$$
\begin{aligned}
& \frac{1}{P e} \frac{d^{2} c_{A}}{d \xi^{2}}-\frac{d c_{A}}{d \xi}-\kappa_{A} c_{A}\left(c_{A}-1+\alpha\right)=0 \\
& \text { at } \xi=0+, \quad \frac{1}{P e} \frac{d c_{A}}{d \xi}=c_{A}-1 \\
& \text { at } \xi=1-, \quad \frac{d c_{A}}{d \xi}=0
\end{aligned}
$$

Eq.(12) was solved numerically by the finite-difference method and the multi-dimensional NewtonRaphson method. The conversion of $\mathrm{NaOH}$ is given by

$$
\left.\eta_{m}=1-c_{A}\right]_{\xi=1}
$$

In Fig. 11, the experimental results $\eta_{e}$ are compared with the conversions calculated $\eta_{m}$. Agreement between them is obtained within \pm 5 percent deviation except for small conversions, where the measure- 


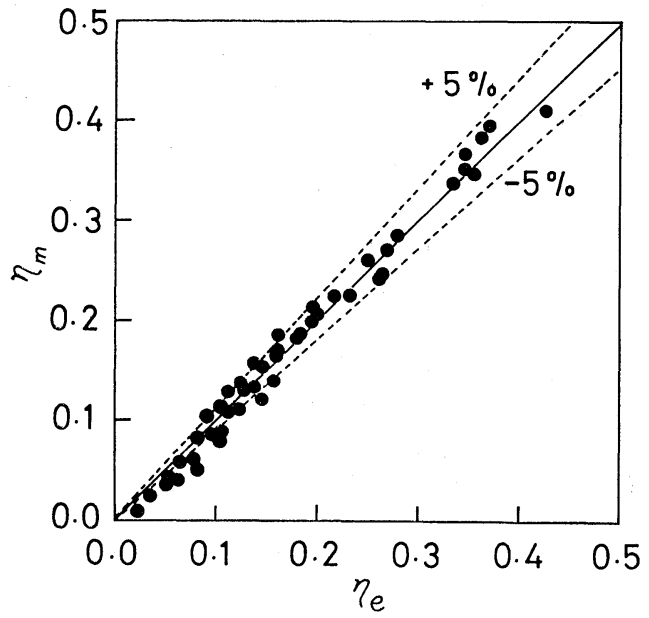

Fig. 11 Comparison of $\eta_{e}$ with $\eta_{m}$

ment error in electric voltage becomes appreciable. This better agreement than the above described results shows that the 1-DDM can be applied to predict steady-state conversion of the reaction at the outlet of a packed-bed reactor.

In the steady-state experiments, a mixture of reactants concerned, say $A$ and $B$, is fed into the packed-bed reactor, and fluid mixing in the reactor contributes partly to the steady-state conversion at the outlet. On the other hand, in the dual-step response method, the reactant $\mathrm{A}$ already present in the process is replaced gradually with the reactant $\mathrm{B}$, for example. Therefore, A and B are mixed only in the packed bed, so that fluid mixing in the reactor fully affects the dual-step responses at the outlet. In effect, the contribution of fluid mixing in the bed to steady-state conversion is different from that to the transient dualstep response.

\section{Conclusion}

The applicability of the one-dimensional dispersion model to the packed-bed chemical reactor is investigated through the results of experiments regarding tracer step responses, dual-step responses with 2nd order irreversible chemical reaction (a saponification of ethyl acetate) and steady-state conversions of the reaction.

The steady-state conversion of the reactor can be well estimated by the model. The model, however, fails to interpret the dynamic behavior of the packed bed with reaction. It is also noted that the dualstep response method is a useful method of testing the applicability of a flow model to a continuous flow system when a chemical reaction is involved.

\section{Acknowledgement}

All the numerical calculations in this paper were carried out at the Computer Center, University of Tokyo. This study was financially supported in part by the foundation of the Ministry of Education of Japan.

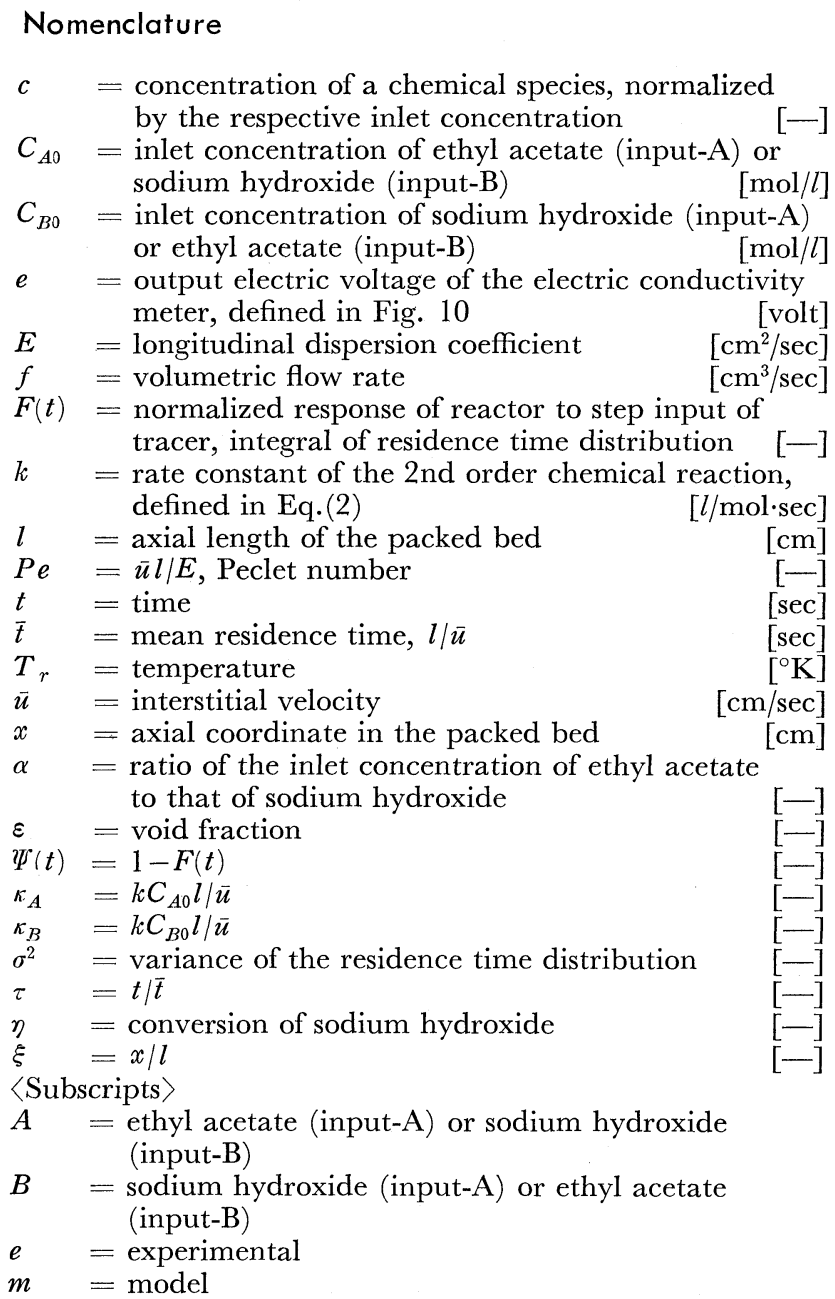

\section{Literature Cited}

1) Brenner, H.: Chem. Eng. Sci., 17, 229 (1962)

2) Cairns, E. J. and J. M. Prausnitz: ibid., 12, 20 (1960)

3) Carberry, J. J. and R. H. Bretton: A.I.Ch.E. Journal, 4, 367 (1958)

4) Cruder, J. E. and A. S. Foss: ibid., 12, 514 (1966)

5) Feick, J. E. and D. Quon: Can. J. Chem. Eng., 48, 205 (1970)

6) Hovorka, R. B. and H. B. Kendall: Chem. Eng. Progr., 56, 58 (1960)

7) Lee, E. S.: Chem. Eng. Sci., 21, 143, 183 (1966)

8) Paris, J. R. and W. F. Stevens: Can. J. Chem. Eng., 48, $100(1970)$

9) Strang, D. A. and C. J. Geankoplis: Ind. Eng. Chem., 50, 1305 (1958)

10) Yagi, S. and T. Miyauchi: Kagaku Kōgaku (Chem. Eng., Japan), 17, 382 (1953)

11) Yano, T. and K. Miyanami: Seigyo Kögaku, 11, 15 (1967)

12) Yano, T. and K. Miyanami: Kagaku Kögaku, 31, 1025 (1967)

13) Yano, T. and K. Miyanami: Seigyo Kōgaku, 13, 111 (1969)

14) I.C.T., Vol. 7, p. 130, McGraw-Hill (1930) 